\title{
Experiências e lições aprendidas no desenvolvimento de capacidades em diplomacia da saúde global
}

\author{
DOI: 10.3395/reciis.v4i1.354pt
}

\begin{abstract}
Ilona Kickbusch
Cientista político, PhD da Universidade de Konstanz, Alemanha. Diretora do Programa de Saúde Global do Graduate Institute of International and Development Studies, Genebra, Suiça. Carreira distinguida na Organização Mundial da Saúde, em níveis regional e global; professora convidada na Universidade de Yale, compartilhando a divisão de saúde global. Assessora titular para o Desenvovimento das Metas do Milênio e Metas de Saúde para a Direção da Organização Panamericana da Saúde.

ilona.kickbusch@graduateinstitute.ch_.

www.graduateinstitute.ch/globalhealth
\end{abstract}

\section{Chantal Berger}

Bacharel em Ciência Política, Mestre em Relações Internacionais pelo Graduate Institute of International and Development Studies, Genebra, Suiça. Gerente de projeto para capacitação no Programa de Saúde Global do Graduate Institute of International and Development Studies. Áreas de pesquisa e de especilaização incluem treinamento em saúde global, governança e diplomacia da saúde global, papel do atores (incluindo parcerias públicoprivada e sociedade civil) e mecanismos de coordenação para a saúde global.

chantal.berger@graduateinstitute.ch

\begin{abstract}
Resumo
Este artigo apresenta alguns componentes essenciais do desenvolvimento de capacidades em diplomacia da saúde global, conforme trabalhado pelo Programa de Saúde Global, e identifica algumas lições aprendidas. O Programa de Saúde Global do Graduate Institute of International and Development Studies de Genebra, é pioneiro nas iniciativas de desenvolvimento de capacidades em Diplomacia da Saúde Global, desde que foi realizado o primeiro curso em Genebra, em 2007. Está também envolvido na criação e realização de treinamentos executivos fora da Europa, com o intuito de refletir, de maneira adequada, a natureza global do curso. Consideram-se novos enfoques e metodologias de desenvolvimento de capacidades e exemplos concretos dos modelos aplicados ao ensino executivo. Isso inclui uma análise do que funciona melhor em termos de parcerias, integração e desenvolvimento dos materiais de ensino. O objetivo é compartilhar experiências em inovação na capacitação no ensino executivo. Cada seção analisa um tópico específico relacionado ao treinamento neste domínio e conclui com várias lições aprendidas.
\end{abstract}

\section{Palavras-chave}

desenvolvimento de capacidades; ensino executivo; diplomacia da saúde global; parcerias; negociações

\section{O objetivo: diplomacia da saúde global}

A diplomacia da saúde global trata dos processos de negociação que configuram e gerenciam o ambiente da política global para a saúde e seus determinantes. Cada vez mais esses processos são tratados não apenas entre especialistas em saúde pública representando ministérios da saúde de estados-nacionais, mas incluem muitos outros atores de importância, por exemplo, de outros ministérios, da sociedade civil, das fundações e do setor privado. A maneira como é conduzida a saúde global (isto é, a "governança da saúde global") está sujeita a mudanças mais amplas na geopolítica do poder. É fundamental compreender essas dinâmicas e responder às mesmas com destreza diplomática.

O processo de formulação de políticas no cenário global realiza-se em muitas instâncias diferentes - com uma quantidade cada vez maior de negociações ocorrendo em ambientes multilaterais, os quais, por sua vez, são preparados por uma ampla gama de instituições regionais, clubes de países e alianças de grupos de atores. Antes 
de chegar ao nível multilateral, porém, é necessário haver uma preparação em nível nacional.

Embora a diplomacia da saúde comporte muitos aspectos e dimensões, a capacitação em diplomacia da saúde global refere-se, em particular, a questões de saúde que cruzam as fronteiras nacionais, são globais pela própria natureza e implicam na necessidade de acordos globais que as contemplem. Profissionais da saúde e das relações exteriores precisam de novas habilidades para negociar regimes globais, acordos e tratados internacionais e ainda para manter relações com uma ampla gama de atores.

O objetivo do treinamento em diplomacia da saúde global é desenvolver as referidas habilidades diplomáticas e de formulação de políticas, envolvendo os participantes em exercícios práticos de negociações, mas também dotando-os de uma base de entendimento com relação às complexidades do panorama atual da saúde global.

A capacitação em diplomacia da saúde global destinase, em especial, aos representantes dos ministérios da saúde, relações exteriores, funcionários de organizações internacionais, atores não-estatais e instituições acadêmicas envolvidas em negociações de saúde que transcendem as fronteiras nacionais. $O$ intuito é aumentar a compreensão que esses atores possuem das dinâmicas da governança da saúde global e aperfeiçoar suas habilidades de negociação. O curso oferece ao amplo grupo de "novos diplomatas da saúde" insights sobre instituições e instrumentos, apresenta mecanismos de coerência política e uma estrutura para negociação.

Assim, os participantes da capacitação em diplomacia da saúde global

- Envolvem-se num processo de aprendizado interativo e multidisciplinar.

- Praticam o pensamento estratégico sobre a interface da saúde global e a diplomacia, e da saúde global com outros setores.

- Aprendem sobre instrumentos e mecanismos para a governança da saúde global.

- Praticam habilidades de negociação através de exercícios de simulações.

- Aplicam seu conhecimento na criação de estratégias de saúde global nacionais ou regionais.

- Debatem valores e questões éticas, assim como outras questões interrelacionadas, no âmbito da diplomacia da saúde global.

Para este fim, muitos métodos são utilizados para transferir conhecimento: estudos de caso, discussões em grupo, simulações e outros exercícios práticos que complementam as apresentações teóricas. Este mix metodológico possibilita o aprendizado prático e teórico e fundamenta a aplicação do conhecimento recém-adquirido. Um corpo docente de elevado nível - que inclui especialistas de renome internacional, diplomatas e representantes de organizações internacionais - interage com os participantes. Em contrapartida, esses participantes trazem suas próprias perspectivas, experiências e qualificações, contribuindo para um processo mútuo de aprendizagem.

Os módulos centrais da capacitação em diplomacia da saúde global incluem, entre outros, aulas sobre a compreensão da natureza da saúde global e da diplomacia da saúde global, história e conceitos de governança da saúde global, saúde e política externa, comércio e saúde, ética e direitos humanos em saúde global, lições aprendidas das negociações, estratégias nacionais de saúde global etc.

\section{A abordagem do desenvolvimento de capacidades}

O modelo de desenvolvimento de capacidades apresentado neste artigo baseia-se num compromisso e parceria de longo prazo estabelecidos com diferentes atores, e não propriamente em atividades isoladas. Ele se ampara em lições aprendidas do Instituto para Trienamento e Pesquisa das Nações Unidas (UNITAR) e do Programa das Nações Unidas para o Desenvolvimento (PNUD) e pode ser exemplificado por meio do modelo de 'desenvolvimento de capacidades' do PNUD (Figura):

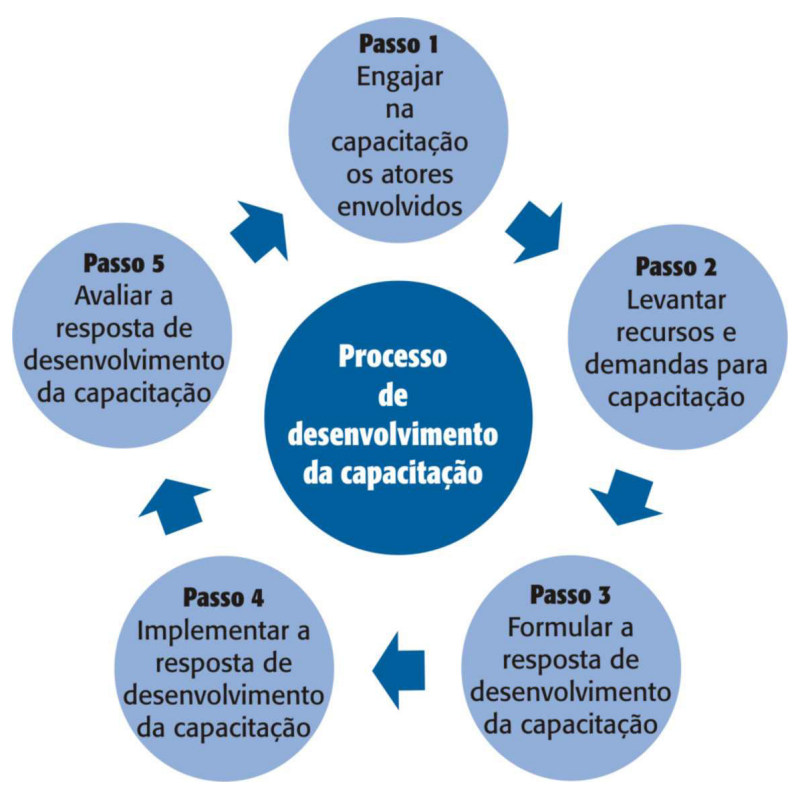

Figura - Modelo de desenvolvimento de capacidades. Fonte: http://www.undp.org/capacity/our_approach.shtml 
Para todo contexto, o processo se inicia pelo estabelecimento de uma visão conjunta com os atores interessados. Em seguida vem a decisão sobre as prioridades de capacitação por meio da ponderação conjunta sobre as necessidades. A partir daí, sugere-se uma resposta e apóia-se a implementação (por exemplo sob a forma de suporte ao ensino ou materiais de ensino). O quinto componente do processo é, necessariamente, o acompanhamento do progresso e a identificação das etapas posteriores. Esta abordagem, então, é adaptada e personalizada às necessidades específicas de cada contexto.

O PNUD define "desenvolvimento de capacidades" como "o processo pelo qual pessoas, organizações e sociedades obtêm, fortalecem e mantêm as qualificações para estabelecer e alcançar seus próprios objetivos de desenvolvimento ao longo do tempo".' Trata-se de uma mudança com relação à abordagem da assistência técnica, para algo muito mais participativo e mobilizador para ambas as partes. Assinala a mudança de uma abordagem pautada pela oferta para outra com enfoque prioritário sobre o lado da demanda. O desenvolvimento de capacidades é reconhecido como um processo de longo prazo e requer adaptação às realidades locais. O esforço se dá para que haja uma apropriação nacional da capacitação, possibilitando que os países desenvolvam e sustentem suas próprias decisões.

\section{A evolução do desenvolvimento de capacidades em diplomacia da saúde global pelo Graduate Institute of International and Development Studies}

O Programa de Saúde Global implementou, de forma bem sucedida, nos últimos três anos uma série de Cursos Executivos em Diplomacia da Saúde Global: três cursos em Genebra em junho de 2007, 2008 e 2009; Pequim em agosto de 2009, com um pré-curso em cooperação com a Organização Mundial da Saúde (OMS), em Genebra em 2008; Nairóbi, em setembro de 2009; e dois cursos em parceria na América do Norte, em Washington DC, Estados Unidos (CDC, UCSF) em 2008 e em Ottawa, Canadá, em 2009 (CSIH). Cada uma dessas experiências trouxe novas ideias, perspectivas e lições aprendidas para o processo de desenvolvimento dessa nova área de estudo.

Genebra é reconhecida internacionalmente como a "capital da saúde global do mundo". Não é apenas a sede da OMS, mas tem também cerca de 80 organizações ativas em saúde global, dentro de suas cidades fronteiriças, assim como uma ampla gama de representações diplomáticas, muitas das quais com adidos de saúde dedicados em tempo integral. E ainda é sede de organizações que exercem um impacto especial sobre a saúde global, como a Organização Mundial do Comércio (OMT), a Organização Internacional do Trabalho (OIT) e a Federação Internacional da Cruz Vermelha e do Crescente Vermelho (IFRC, na sigla em inglês). Desta forma, trata-se de um lugar único para o ensino executivo de questões de saúde global em geral e de diplomacia da saúde global em particular. O ambiente propicia a exposição dos participantes de todo o mundo a uma grande diversidade de atores da saúde global e diplomacia.

O curso de Genebra em Diplomacia da Saúde Global no Graduate Institute of International and Development Studies é, de longe, o mais internacional em termos de participantes com uma média de 20 participantes, representativos de todas as regiões do mundo, em cada curso. Também possibilita o envolvimento de uma ampla gama de membros de corpo docente, oriundos das organizações e missões sediadas em Genebra, permitindo visitas e simulações na OMS. Como resultado da diversidade do corpo docente e de participantes, o curso de Genebra atua como trampolim para parcerias, possibilitando uma troca de idéias e visões entre países e instituições.

Cada curso é avaliado tanto no papel como em discussões em aula - as avaliações têm sido bastante positivas e as sugestões dos participantes bastante úteis para o desenvolvimento de cursos futuros. Até agora, cerca de 200 pessoas receberam treinamento em Diplomacia da Saúde Global em nível mundial com o envolvimento do Graduate Institute of International and Development Studies.

\section{O Curso de Genebra: algumas lições aprendidas}

Em relação ao corpo docente - É essencial ter um corpo docente interdisciplinar que represente diferentes níveis de desenvolvimento e organizações. Ademais, é essencial ter profissionais de Diplomacia da Saúde Global que ensinem e compartilhem as suas experiências de vida real.

Em relação aos participantes - Os participantes precisam ser bem diversificados em termos de composição, para fomentar o aprendizado mútuo. O trabalho prático e real nos componentes mais técnicos do curriculum se mostrou muito útil, de maneira que eles podem se preparar antecipadamente, assegurando que todos tenham um nível similar de compreensão. Para aproveitarem melhor seu tempo em Genebra, os participantes devem ser encorajados a se envolver com peritos e instituições internacionais na região, facilitando assim o networking e as experiências de primeira mão. 


\section{Desenvolvimento de parcerias para iniciativas de treinamento}

O curso de Diplomacia da Saúde Global foi elaborado com uma perspectiva de parceria a longo prazo desde o lançamento do primeiro curso, envolvendo uma instituição parceira em cada um dos cursos de verão em Genebra. Em 2007, o curso de Genebra foi realizado em parceria com o Brasil, em 2008 com o Quênia e o curso de 2009 com representantes da Tailândia e da Índia. Este modelo resultou em um curso organizado no Quênia, com potenciais cursos planejados para a Índia e a Tailândia em 2010. O Brasil começou a desenvolver seus próprios cursos. Outros cursos também foram realizados em parceria com a China, os Estados Unidos e Canadá no período compreendido entre 2008 e 2009.

O Programa de Saúde Global do Graduate Institute of International and Development Studies conseguiu levar o curso de Diplomacia da Saúde Global a navegar em três níveis de desenvolvimento com participantes majoritariamente nacionais: mundo desenvolvido (Estados Unidos e Canadá), economias emergentes (China e cooperação com o Brasil) e países em desenvolvimento (Quênia). Embora o curso no Quênia tenha sido previsto originalmente como um curso regional, ficou evidente, no decorrer dos preparativos, que um curso em nível nacional seria uma primeira etapa. No entanto, uma vez tendo sido criada a consciência da importância da diplomacia da saúde global - uma grande maioria dos participantes expressou a necessidade de expandir o curso para o nível regional, também com o intuito de fortalecer o papel do Quênia na região. Temos aí algo que difere das abordagens das economias emergentes, onde já existe a compreensão geral da Diplomacia da Saúde Global e há uma visão nacional clara sobre as necessidades de desenvolvimento de capacidades. A amplitude dos contextos nacionais de países como o Brasil e a China também varia em relação a um país menor, como o Quênia. Para expandir o modelo nacional, as abordagens regionais também serão exploradas com a Europa (União Europeia) e em cooperação com os Centros de Controle de Doenças (Centers for Disease Control - $C D C$ ) e Universidade de San Diego, na Califórnia, Estados Unidos.

Alguns dos atuais parceiros são também membros do Consórcio para a Diplomacia da Saúde Global, rede composta por 14 instituiç̃es acadêmicas e de pesquisa de todo o mundo. Lançar mão dos recursos do Consórcio também facilita parcerias no próprio processo de ensino. Tanto o curso na China como no Quênia fundamentam-se em um "modelo tripartite" em que os membros do corpo docente eram compostos de três parceiros de diferentes continentes. $\mathrm{O}$ curso da China foi realizado em parceria com o corpo docente do Programa de Saúde Global do Instituto de Genebra/Suíça, Instituto de Saúde Global de Pequim, China, e Fiocruz/Brasil. No Quênia, houve uma cooperação entre o Programa de Saúde Global Genebra/Suíça, Fundação de Saúde Pública da Índia e Universidade de Nairóbi. Esta abordagem enriquece não apenas os processos de intercâmbio e aprendizagem, mas também fortalece o entendimento e a parceria entre as instituições. Ademais, tem a possibilidade de resultar na criação e adaptação do curso em novos países e contextos, atendendo, assim, a diferentes necessidades.

Todos os cursos caracterizam-se também por um número de outras parcerias, por exemplo, com relação a financiamento, atores envolvidos nos estudos de caso e simulações, palestrantes convidados, co-organizadores e coordenações adjuntas.

\section{Parcerias: algumas lições aprendidas}

A construção de parcerias é fundamental e os cursos da China e do Quênia foram tributos a esse aspecto. O modelo tripartite funciona bem e precisa ser ainda mais fortalecido, sendo essencial, para isso, que o corpo docente receba instruções antes do curso, para que todos venham com uma perspectiva comum. $\mathrm{O}$ trabalho preparatório para os cursos, tanto em Genebra como em outros países é extenso, exige tempo e precisa ser bem planejado. A adaptação dos cursos aos diferentes contextos é também essencial e, neste ponto, os parceiros locais podem ser muito úteis, ajudando a compreender as realidades locais e aconselhando na adaptação do curriculum. Em especial, os conceitos nacionais de saúde e de diplomacia precisam ser bem compreendidos pelo corpo docente que chega do exterior. Por exemplo, a tradição chinesa da diplomacia é fundamentalmente diferente do conceito norte-americano ou europeu. É preciso identificar instituições parceiras fortes para que o treinamento prossiga e é preciso também assegurar a continuidade de orientações especializadas (sob demanda) oferecidas pelo Instituto de Pós-Graduação.

\section{Integração do curriculum}

Outra característica importante de todos os cursos de diplomacia da saúde global organizados pelo Graduate Institute of International and Development Studies é sua abordagem em prol da integração. O objetivo - difícil de alcançar, é preciso dizer - é fazer com que os cursos sejam organizados em conjunto por parceiros da saúde e das 
relações exteriores e fazer com que tanto participantes como corpo docente reflitam este mix.

Visando fundamentar-se na perspectiva conceitual da diplomacia da saúde global de interface da saúde, relações exteriores, desenvolvimento, comércio e pesquisa, os participantes do curso são selecionados desses setores. O curso do Quênia com sua composição interministerial é um bom exemplo: os participantes eram oriundos do Ministério da Saúde Pública e Saneamento, do Ministério de Serviços Médicos, do Ministério de Comércio, do Ministério das Relações Exteriores, do Instituto da Diplomacia e Estudos Internacionais, da Universidade de Nairóbi e de ONG. Em consequência, o conceito de diplomacia da saúde global integra-se nessas diferentes instituições e o curso atua como um primeiro passo na construção de uma coerência nacional entre diferentes atores em nível nacional. O curso na China não foi assim tão amplo, mas apresentou outras características - como a participação de alto nível do Ministério da Saúde e do Ministério das Relações Exteriores nos debates, o envolvimento do governo suíço e de sua embaixada, assim como do Secretário de Estado suíço para a Saúde, e uma forte representação regional das províncias.

A integração também se refere à combinação do curriculum da diplomacia da saúde global em outras instâncias e escolas. Assim, em Genebra módulos específicos do curso são integrados a outros cursos, tais como treinamento para diplomatas ou escolas de verão em saúde global, e em programas do Instituto, como nos Mestrados de Estudos Avançados e Mestrados Executivos em Negociação Internacional e Formulação de Política.

Mediante o desenvolvimento de materiais de treinamento que possam se adaptar a uma grande variedade de contextos, a integração permanece como um objetivo de longo prazo do programa para além de Genebra. O Programa de Saúde Global está elaborando materiais de treinamento que incluem um manual de treinamento, estudos de caso para ensino, um livrotexto e está comprometido em um planejamento de longo prazo para desenvolver um curso online. Essas ferramentas de ensino ampliarão muitíssimo a produtividade e o alcance do curriculum da diplomacia da saúde global. O objetivo do manual de treinamento também é desenvolver oficinas de treinamento para treinadores (ToT), para que toda uma diversidade de países possa adaptar o conteúdo segundo suas necessidades nacionais e executar seus próprios treinamentos em nível nacional ou regional. Essas abordagens de parceria e integração são parte de uma implementação de capacitação mais ampla.

\section{Integração: algumas lições aprendidas}

É importante fazer um esforço ainda maior para que os cursos sejam organizados em conjunto com um parceiro da saúde e das relações exteriores e ter ambos reflitindo este mix. Os participantes também tem interesse numa rede de exalunos que agora foi estabelecida para fomentar a comunicação entre os graduados do curso de todo o mundo e incentivar ainda mais a conscientização sobre campo de estudo.

\section{Inovação em implementação de competências}

O conceito de "diplomacia da saúde global" ainda é um conceito novo, inovador, e carece de sensibilização. A maior conscientização sobre o entendimento e significado do conceito, antes de levar os cursos para fora de Genebra, foi essencial para garantir uma audiência diversificada e um êxito geral. Para complementar o quadro de desenvolvimento de capacidades, serão elaboradas diretrizes de preparação do curso.

Os cursos, de maneira geral, destinam-se aos profissionais de carreira (médio e alto escalão) e também titulares que trabalham em questões ligadas à saúde, em diferentes instituições, especialmente do setor saúde e de relações exteriores. As experiências mostraram que esta composição varia muito. Nos cursos de Genebra, os participantes são profissionais de carreira e titulares, o que possibilita não apenas aprendizado no curso, como também aprendizado mútuo entre os participantes - uma das características mais apreciadas dos cursos de Genebra onde os participantes também são oriundos de ONG e do setor privado. Na China, a audiência compunha-se de cidadãos oriundos (sobretudo) dos departamentos de saúde e relações exteriores, de todo o país (inclusive representantes das províncias) e o curso os reuniu na capital. No Quênia - como exposto acima - os participantes eram bastante misturados e, ao contrário da China, eram todos da própria capital, Nairóbi. No entanto, em ambos os casos, os participantes que de outra forma não poderiam ter se encontrado ou discutido juntos, estavam interagindo e aprendendo uns com os outros pela primeira vez. Temos aí uma característica fundamental de todos os cursos.

A partir da combinação de experiência e 'senioridade' dos participantes, o desenvolvimento de capacidades em diplomacia da saúde global resultou em que os participantes se tornassem membros do corpo docente e/ou organizadores de cursos em suas localidades domésticas, como no caso de Brasil e Quênia. 
Desenvolvimento de capacidades: algumas lições aprendidas

O curso, para um bom funcionamento, comporta de 25 a 30 participantes. É muito importante insistir no mix de participantes; em idade, nacionalidade, filiação a organizações/ ministérios, gênero e experiências profissionais. Isso nutre a oportunidade de aprendizado mútuo e troca de experiência entre os participantes. Para os cursos nacionais, é essencial contar com a inclusão de outros países/exemplos. Sobre o conteúdo do curso, exercícios interativos, tais como trabalhos em grupo e simulações têm sido muito apreciadas pelos participantes para uma aprendizagem ativa.

\section{Desenvolvimento de habilidades de negociação}

À medida que a saúde se torna uma questão de política externa e é negociada em diversos espaços, envolvendo um número variado de atores interessados, a necessidade de habilidades de negociação é fundamental. O treinamento de habilidades de negociação, tradicionalmente, é reservado aos diplomatas e delegações de países, e foge à regra como habilidade a ser desenvolvida por representantes de ONG, secretariados de organizações internacionais, a academia ou o setor privado. Nesse momento, em que cada vez mais atores sentam-se à mesa das negociações internacionais, há a necessidade de fortalecer suas habilidades para apresentar e argumentar de maneira efetiva sobre suas posições nessas negociações. O curriculum em diplomacia da saúde global, assim, inclui uma simulação de negociação de um dia de duração, intensiva, visando desenvolver algumas dessas estratégias e apresentar o desenho de alguns dos principais obstáculos ao êxito das metas de negociações. Normalmente o treinamento tem a forma de uma simulação participativa, que expõe os participantes a uma situação de vida real. Estimula-se ainda o aprendizado com análises e troca de experiências.

\section{Habilidades de negociação: algumas lições aprendidas}

A oportunidade de contar com especialistas já experientes em negociações de saúde aumenta muito a qualidade de aprendizado nos exercícios para desenvolver habilidades de negociação. Os participantes verdadeiramente apreciaram as experiências pessoais partilhadas e a aplicabilidade dessas experiências nas negociações em que eles próprios possam estar envolvidos. Se possível, uma boa abordagem para os treinamentos é assegurar a participação de um treinador profissional em habilidades de negociação, que possa apresentar algumas técnicas gerais sobre negociação. $\mathrm{O}$ referido profissional precisa ser acompanhado por um especialista em saúde que possa fazer as associações das experiências à perspectiva da saúde global, assim enriquecendo o treinamento básico.

O exercício de simulação é central e deve ser muito bem preparado. Abrange uma clara definição das posições das delegações representativas escolhidas, assim como os principais componentes de um texto ou tópico a negociar. Os exercícios de dinâmicas de grupo podem ser extraídos de exemplos fictícios ou baseados na vida real; cada um tem suas vantagens.

\section{Elaborando estratégias nacionais}

Mais um dos objetivos do curso é fazer com que os participantes reflitam em seus próprios países a perspectiva da saúde global e de que maneira ela é coordenada para fazer frente aos seus desafios intrínsecos. Tanto na China como no Quênia um dos principais resultados dos respectivos cursos foi o comprometimento, por parte dos organizadores dos cursos locais e dos participantes no sentido de dar continuidade ao trabalho de desenvolvimento de uma estratégia nacional de saúde global. Pela partilha de ferramentas práticas e exemplos, os participantes são estimulados a uma reflexão sobre a estrutura necessária e os atores envolvidos no desenvolvimento de uma estratégia nacional de saúde global. Normalmente os participantes são apresentados a dois modelos nacionais atuais de estratégias de saúde global: Suíça e Reino Unido. Esses exemplos, cujos processos de negociação e conteúdo são explicados por especialistas, podem servir como fontes de inspiração para o desenvolvimento de novas estratégias, nacionais ou regionais. Os debates levaram tanto a China como o Quênia a um comprometimento concreto e os dotaram das orientações necessárias que esquematizam as próximas etapas e elaboram cronologias para o desenvolvimento de referida estratégia nacional.

\section{Estratégias nacionais: algumas lições aprendidas}

Os participantes empolgam-se com ideias e ferramentas que possam aplicar em seus contextos. O ditado "Saúde Global começa em casa" tornou-se central aos cursos - tanto em Genebra como em outras partes. Uma estratégia nacional de saúde global é uma abordagem dessa ordem. No curso de Genebra, em que os participantes são oriundos de uma variedade de países e experiências, em geral selecionamse alguns para apresentar a ótica do seu país com relação à saúde global e a refletir, a partir daí, como seria possível desenvolvê-la em uma estratégia de saúde global mais formal. Por exemplo, no curso de Genebra de 2009, a Tailândia fez uma apresentação do seu modelo particular de 
desenvolvimento de capacidades em saúde global, que se mostrou uma grande oportunidade de aprendizado conjunto.

\section{Desenvolvendo materiais de ensino}

Houve um ganho expressivo de experiência a partir do desenvolvimento dos conteúdos do curso e das devidas adaptações desses conteúdos aos diferentes contextos. Muitos desses estão sendo consolidados e serão capturados em um manual de treinamento, assim como em um curso de treinamento via web, que estão em desenvolvimento no presente momento.

A maioria dos módulos básicos permanece sempre idêntica (mas sofre adaptações regulares), enquanto outros módulos são modificados segundo os diferentes contextos. O enfoque e a priorização das alterações nos módulos dependem da consciência geral com relação à saúde global, o conhecimento existente dos obstáculos à saúde global e governança da saúde global e tópicos afins. O Instituto de Genebra permanece como o eixo central para a introdução de novos elementos do curso, como por exemplo o módulo sobre saúde e mudanças climáticas, no curso do verão de 2009. É aqui também que se produz um conjunto atualizado de leituras que ficam então disponibilizadas em um CD ROM para os participantes. Com o intuito de facilitar um treinamento mais amplo e um efeito multiplicador, o manual de treinamento reunirá esses diferentes módulos.

O fato de disponibilizar os materiais de ensino aos parceiros para seu próprio uso será um elemento de enorme importância. Os parceiros serão incentivados a adaptar os materiais para seus próprios cursos em um contexto específico, o que por sua vez possibilitará a organização de oficinas de "treinamento dos treinadores", com os antigos e novos parceiros.

\section{Publicações}

Finalmente, as publicações são um produto importante resultado desses cursos. Já foram publicados um número significativo de $\operatorname{artigos}^{3}$ sobre diplomacia da saúde global e a iniciativa conhecida como Publicações Científicas (em inglês, Scientific Publications), um portal da internet destinado a publicar artigos científicos de elevada qualidade e de acesso público, já encomendou uma série de livros sobre diplomacia da saúde global. Esta série prevê a publicação, entre outras, de uma introdução à diplomacia da saúde global. Além disso, está em preparação um livro-texto sobre Diplomacia da Saúde Global.

\section{$\mathrm{O}$ caminho à frente}

De todas as experiências obtidas pelo Programa de Saúde Global ficou evidente que a demanda por desenvolvimento de capacidades em diplomacia da saúde global existe por todo o mundo. A visão de futuro é amparar-se nestas lições aprendidas a fim de criar uma abordagem adaptável e sustentável da diplomacia da saúde global, primeiramente mediante o lançamento de cursos-piloto em diversos lugares do mundo e, eventualmente, por meio de sessões de ToT com um manual de treinamento bem desenvolvido para que o curriculum se torne autossustentável. Num mundo em constantes e rápidas mudanças, onde um número de novos atores envolvem-se em processos de negociação de políticas em uma variedade de ambientes, faz-se presente mais do que nunca a necessidade de treinamento em diplomacia da saúde global. É a esperança do Programa de Saúde Global que, pela troca e partilha das experiências e lições aprendidas com os parceiros de todas as partes do mundo, seja possível realizar uma estratégia duradoura para a consecução do desenvolvimento de capacidades.

\section{Notas}

1. Grupo de Desenvolvimento das Nações Unidas (United Nations Development Group) (agosto de 2009). "United Nations Development System: A Collective Approach to Supporting Capacity Development".

2. Para obter mais informações sobre o Consortium for Global Health Diplomacy, consulte http://graduateinstitute.ch/globalhealth/ page5058.html

3. Consulte http://graduateinstitute.ch/globalhealth/home/page 4125.html 